\title{
Effect of Tungsten Doping on Catalytic Properties of Niobium Oxide
}

\author{
Franciane P. Cardoso, ${ }^{a}$ Andre E. Nogueira, ${ }^{a}$ Patrícia S. O. Patrício ${ }^{*, b}$ \\ and Luiz C. A. Oliveira ${ }^{c}$ \\ ${ }^{a}$ Departamento de Química, Universidade Federal de Lavras, CP 3037, \\ 37200-000 Lavras-MG, Brazil \\ ${ }^{b}$ Centro Federal de Educação Tecnológica, CEFET, Av. Amazonas, 5253, \\ 30421-169 Belo Horizonte-MG, Brazil \\ 'Departamento de Química, ICEx, Universidade Federal de Minas Gerais, \\ Av. Amazonas, 6627, 31270-901 Belo Horizonte-MG, Brazil
}

\begin{abstract}
Um novo material à base de nióbia $\left(\mathrm{Nb}_{2} \mathrm{O}_{5}\right)$ foi sintetizado e quimicamente modificado para oxidar compostos orgânicos em meio aquoso, na presença de $\mathrm{H}_{2} \mathrm{O}_{2}$. A nióbia foi modificada por dopagem com tungstênio e também tratamento com $\mathrm{H}_{2} \mathrm{O}_{2}$ com o intuito de potencializar suas propriedades oxidativas. A investigação dos produtos gerados pela oxidação do azul de metileno, usando a técnica de espectroscopia de massas com ionização por eletrospray (ESI-MS), mostrou que o corante foi sucessivamente oxidado produzindo diferentes compostos intermediários. A sucessiva hidroxilação durante o processo oxidativo indica a alta reatividade dos radicais hidroxilas que são gerados, envolvendo $\mathrm{H}_{2} \mathrm{O}_{2}$ sobre a superfície do grão de nióbia dopada com W. Estes resultados sugerem fortemente que $\mathrm{o}_{2} \mathrm{O}_{2}$ pode regenerar in situ o grupo peróxido, permanecendo ativo no sistema.
\end{abstract}

A novel material based on niobia $\left(\mathrm{Nb}_{2} \mathrm{O}_{5}\right)$ was synthesized to oxidize an organic compound in aqueous medium in the presence of $\mathrm{H}_{2} \mathrm{O}_{2}$ after chemical modifications. Niobia was modified by doping with tungsten and also treating with $\mathrm{H}_{2} \mathrm{O}_{2}$ in order to maximize the oxidative properties of this oxide. The analysis of the products from methylene blue dye oxidation with electrospray ionization mass spectrometry (ESI-MS) showed that the dye was successively oxidized to different intermediate compounds. The successive hydroxylation during this oxidation strongly suggests that highly reactive hydroxyl radicals are generated involving $\mathrm{H}_{2} \mathrm{O}_{2}$ on the W-doped niobia grain surface. These results strongly suggest that the $\mathrm{H}_{2} \mathrm{O}_{2}$ can regenerate in situ the peroxo group remaining active the system.

Keywords: niobia, tungsten, catalytic oxidation, organic contaminant

\section{Introduction}

Currently, the pollution of water resources is a serious problem in various developed countries. Among several productive sectors responsible for the degradation of aquatic environmental quality, the textile industries stand out, because they generate a great volume of wastewater with a high organic load and biochemical oxygen demand, low dissolved oxygen concentrations, strong coloration and low biodegradability. These wastewaters also possess great propensity to alter biological cycles, due to their toxicity and carcinogenic and mutagenic potential. ${ }^{1}$

*e-mail: patriciapatricio@ cefetmg.br
The conventional techniques applied to the treatment of textile wastewater, such as coagulation/flocculation, membrane separation and adsorptive processes (using activated carbon for instance), simply concentrate or transfer the pollutant from one phase to another, creating a secondary pollutant, which degradation still remain a problem to be solved. Biological treatment is not the solution for this problem, due to the low biodegradability or toxicity of various dyes. ${ }^{2,3}$ For that reason, the development of new technologies is necessary to have more efficient and cost effective degradation of organic molecules, such as the textile dyes.

In that context, in recent years systems based on $\mathrm{Nb}_{2} \mathrm{O}_{5}$ have been receiving special attention, due to their 
high catalytic activity in several important chemical processes, such as: dehydration, hydration, hydrolysis, condensation, dehydrogenation, alkylation, photochemical, electrochemical, polymerization and organic compound oxidation reactions. ${ }^{4-7}$ Another interesting aspect is that their natural occurrence and relatively high abundance in the earth's crust (approximately $20 \mathrm{mg} \mathrm{kg}^{-1}$ ) make their use as a low cost material. ${ }^{8}$ Furthermore, niobium and other transition metals, such as, Mo, $\mathrm{W}, \mathrm{V}, \mathrm{Ta}$, when in contact with hydrogen peroxide $\left(\mathrm{H}_{2} \mathrm{O}_{2}\right)$, form active species called peroxo group. ${ }^{9}$ These species have been attracting special attention due to their chemical coordination, biological importance (antitumor activity), as well as their role as catalyst in various reactions. ${ }^{10}$ Moreover, they are potentials oxygen donors to the organic substrate in aqueous medium. These groups can act as stoichiometric oxidizers or as catalysts in the presence of oxidizing agents, such as $\mathrm{H}_{2} \mathrm{O}_{2}$, used to regenerate those species in situ. ${ }^{11}$

In that direction, the objective of this work is to present the application of a synthetic niobium oxide (pure $\mathrm{Nb}$ ) and one modified by the doping with tungsten $(\mathrm{NbW})$, on the oxidation of methylene blue dye in the presence of $\mathrm{H}_{2} \mathrm{O}_{2}$. In addition, the surface of the $\mathrm{NbW}$ catalyst was previously treated with $\mathrm{H}_{2} \mathrm{O}_{2}$ (hereafter $\mathrm{NbW} / / \mathrm{H}_{2} \mathrm{O}_{2}$ ) for the generation of surface oxygenated groups, in order to improve the catalytic activity for pollutant oxidation.

\section{Experimental}

\section{Synthesis and modification of niobia}

The niobium oxide (pure $\mathrm{Nb}$ ) was prepared by dropping slowly $20 \mathrm{~mL}$ of $\mathrm{NaOH}\left(1 \mathrm{~mol} \mathrm{~L}^{-1}\right)$ in a $500 \mathrm{~mL}$ Teflon becker containing $100 \mathrm{~mL}$ of a $\mathrm{NH}_{4}\left[\mathrm{NbO}\left(\mathrm{C}_{2} \mathrm{O}_{4}\right)_{2}\left(\mathrm{H}_{2} \mathrm{O}\right)\right]$ $\left(\mathrm{H}_{2} \mathrm{O}\right)_{\mathrm{n}}$ solution (17.9 g) (CBMM- Brazilian Metallurgy and Mining Company, Araxá-MG) at $70^{\circ} \mathrm{C}$ under vigorous stirring. Soon afterwards it was vacuum-filtered and washed with distilled water until $\mathrm{pH} 7$. The material was oven-dried at $90{ }^{\circ} \mathrm{C}$ for $12 \mathrm{~h}$ and soon afterwards calcined at $600{ }^{\circ} \mathrm{C}$ for $3 \mathrm{~h}$. For the doped material, the previous procedure was followed, however, with the addition of the salt $\mathrm{Na}_{2} \mathrm{WO}_{4} \cdot 2 \mathrm{H}_{2} \mathrm{O}(1.6 \mathrm{~g})$, in order to obtain $5 \% \mathrm{~W}$ in mass.

The synthetic niobia doped with tungsten $(\mathrm{NbW})$ was submitted to hydrogen peroxide treatment in order to generate more active surface sites according to recent works. ${ }^{12,13}$ This treatment was made adding $300 \mathrm{mg}$ of niobia, $4 \mathrm{~mL}$ of $\mathrm{H}_{2} \mathrm{O}_{2}(30 \% \mathrm{~V} / \mathrm{V})$ and $80 \mathrm{~mL}$ of distilled $\mathrm{H}_{2} \mathrm{O}$, leaving them in contact for $30 \mathrm{~min}$. Soon afterwards the material was vacuum-filtered, washed with distilled $\mathrm{H}_{2} \mathrm{O}$ and oven-dried for $12 \mathrm{~h}$ at $90^{\circ} \mathrm{C}$. A simplified scheme of the niobia modification by doping with $\mathrm{W}$ and the $\mathrm{H}_{2} \mathrm{O}_{2}$ treatment is illustrated in the Figure 1. The treatment of $\mathrm{Nb}^{5+}$ soluble salts with $\mathrm{H}_{2} \mathrm{O}_{2}$ makes the solution yellowish due to the formation of peroxo-niobium groups. ${ }^{9,14}$ The color change was observed, same dealing with solid material as can be seen in the photograph of Figure 2.

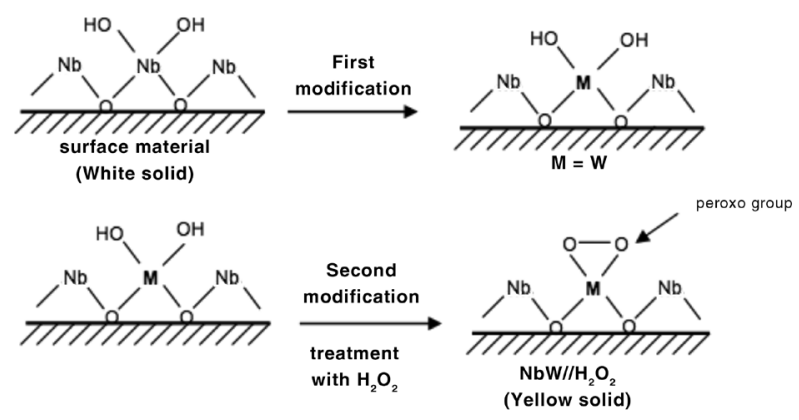

Figure 1. Simplified scheme of the niobium oxide modification by doping with $\mathrm{W}$ and the $\mathrm{H}_{2} \mathrm{O}_{2}$ treatment.

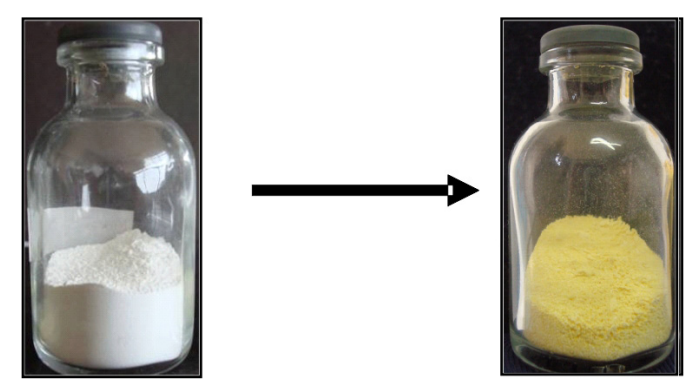

Figure 2. Photograph of white (before $\mathrm{H}_{2} \mathrm{O}_{2}$ treatment) and yellow catalysts (after $\mathrm{H}_{2} \mathrm{O}_{2}$ treatment) (see online version).

\section{Materials characterization}

XRD measurements of the samples were carried out with a SIEMENS D-5000, powder diffractometer at 40-50 mA, equipped with a variable slit, a diffracted beam monochromator, and a scintillation counter. The diffractograms were recorded in the $2 \theta$ range $\left(10-80^{\circ}\right)$ with a speed of $0.5^{\circ} \min ^{-1}$ using $\mathrm{Cu} \mathrm{K} \alpha$ radiation (1.5418 $\mathrm{A}$ ). TPR experiments were performed in a CHEMBET 3000 equipment with $20 \mathrm{mg}_{\text {sample }}$ under $80 \mathrm{~mL} \mathrm{~min}^{-1} \mathrm{H}_{2}(5 \%) / \mathrm{N}_{2}$ with heating rate of $10^{\circ} \mathrm{C} \mathrm{min}-1$. Spectra were recorded in a Digilab (Excalibur, FTS 3000) FTIR spectrometer and processed with IRDM (IR data manager) software using the $\mathrm{KBr}$ pellet technique. Morphological analysis was also performed by scanning electron microscopy (SEM Leo Evo model 40XVP).

Catalytic tests: organic dye oxidation

\section{UV-Vis spectroscopy studies}

Oxidation tests were conducted with a model organic molecule, methylene blue dye (MB), in aqueous medium 
using pure $\mathrm{Nb}, \mathrm{NbW}$ and $\mathrm{NbW}$ treated with $\mathrm{H}_{2} \mathrm{O}_{2}$, called $\mathrm{NbW} / / \mathrm{H}_{2} \mathrm{O}_{2}$.

The oxidation tests were carried out at $25{ }^{\circ} \mathrm{C}$, using $9.9 \mathrm{~mL}$ of a solution containing the $\mathrm{MB}$ dye $\left(50 \mathrm{mg} \mathrm{L}^{-1}\right)$ and $10 \mathrm{mg}$ of catalyst, in the presence of $\mathrm{H}_{2} \mathrm{O}_{2}$ $50 \% \mathrm{~V} / \mathrm{V}(0.1 \mathrm{~mL})$. The discoloration kinetics of the MB dye was monitored by UV-Vis spectroscopy (ShimadzuUV-1601 PC) at $665 \mathrm{~nm}$, the characteristic wavelength of MB dye.

\section{ESI-MS studies}

The possible oxidation products were analyzed by electrospray ionization mass spectrometry. For that, an ion trap electrospray ionization mass spectrometer, (Agilent-1100) was used. The samples were inserted in the equipment by infusion, at a flow rate of $15 \mu \mathrm{L} \mathrm{min}{ }^{-1}$, with charge control in the quadrupole (ICC) adjusted to 30,000 and positive mode. The drying gas $\left(\mathrm{N}_{2}\right)$ temperature was $325{ }^{\circ} \mathrm{C}$, flow rate $5 \mathrm{~L} \mathrm{~min}^{-1}$, ion extraction potential $-3.500 \mathrm{~V}$.

\section{Results and Discussion}

\section{Materials characterization}

In order to characterize the catalysts after doping with tungsten and treating with $\mathrm{H}_{2} \mathrm{O}_{2}$, infrared spectra (Figure 3) of the materials were obtained.

A band at $3412 \mathrm{~cm}^{-1}$ assigned to the $\mathrm{OH}$ stretching of $\mathrm{Nb}-\mathrm{OH}$ and a typical signal at $3140 \mathrm{~cm}^{-1}$, due to the bulk hydroxyl stretching. A broad band at $1637 \mathrm{~cm}^{-1}$ related to adsorbed water on the $\mathrm{Nb}_{2} \mathrm{O}_{5}$ surface, a band at $870 \mathrm{~cm}^{-1}$ assigned to $\mathrm{Nb}-\mathrm{O}$ or $\mathrm{W}-\mathrm{O}$ stretchings, and bands between 500 and $950 \mathrm{~cm}^{-1}$ corresponding to $\mathrm{Nb}-\mathrm{O}-\mathrm{Nb}$ and $\mathrm{W}-\mathrm{O}-\mathrm{W}$ angular vibrations also can be observed..$^{15} \mathrm{~A}$ band at approximately $537 \mathrm{~cm}^{-1}$ was also observed, related to the presence of $\mathrm{O}-\mathrm{O}$ type asymmetrical stretching bonded

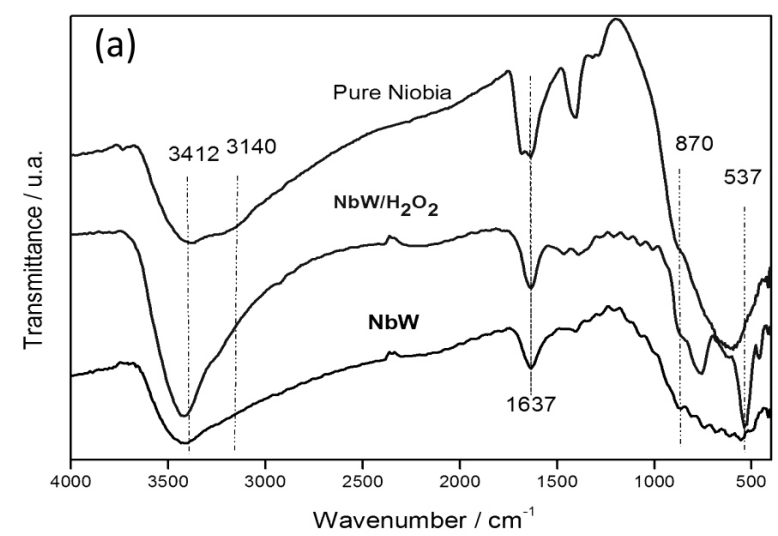

to the metal $\left(\mathrm{Nb}\left(\mathrm{O}_{2}\right)\right)$ and even at $820-870 \mathrm{~cm}^{-1}$ referring just to the $\mathrm{O}-\mathrm{O}$ stretching (peroxo). ${ }^{9}$ Qualitatively, a decrease in the signal from superficial $\mathrm{OH}$ vibration can be observed due to the previous treatment with hydrogen peroxide. Reflectance spectra were obtained in the attempt to more efficiently identify the surface groups (Figure 3b). Bands can be observed regarding to stretching of internal hydroxyls at $3202 \mathrm{~cm}^{-1}$, now also observed in the samples doped with $\mathrm{W}$, and superficial at $3488 \mathrm{~cm}^{-1}$. In fact, those bands were more evident in the diffuse reflectance spectra, compared to those of transmittance in Figure 3a. An intense band is observed at $1696 \mathrm{~cm}^{-1}$ regarding the angular deformation of $\mathrm{O}-\mathrm{H}$ of $\mathrm{H}_{2} \mathrm{O}$ adsorbed or bonded to the surface, for the samples pure $\mathrm{Nb}$ and $\mathrm{NbW}$. However, the niobia doped with $\mathrm{W}$ previously treated with $\mathrm{H}_{2} \mathrm{O}_{2}$ (NbW// $\mathrm{H}_{2} \mathrm{O}_{2}$ ) displays an abrupt fall of that band intensity. That result can indicate that the previous treatment with $\mathrm{H}_{2} \mathrm{O}_{2}$ reacts with the original $\mathrm{OH}$ surface groups. In addition, the bands in 1417 and $1275 \mathrm{~cm}^{-1}$ are assigned to the residual organic component $\left(\mathrm{NH}_{4}\left(\mathrm{NbO}\left(\mathrm{C}_{2} \mathrm{O}_{4}\right)_{2}\left(\mathrm{H}_{2} \mathrm{O}\right)\right)\left(\mathrm{H}_{2} \mathrm{O}\right)_{\mathrm{n}}\right)$ of neat niobia precursor. ${ }^{15}$

The morphology of the materials was studied by scanning electronic microscopy. The micrographs of the materials are presented in Figure 4.

The micrographs of the samples pure $\mathrm{Nb}$ (Figure 4a) and $\mathrm{NbW}$ (Figure 4b) clearly show a modification in the morphological characteristics after the doping with W. Pure $\mathrm{Nb}$ presents irregular sized crystals, while the NbW sample presents smaller crystals and with greater regularity. Those results are in agreement with the alterations obtained in oxides after the doping with different metals. ${ }^{16}$ It can also be observed that the pre-treatment with $\mathrm{H}_{2} \mathrm{O}_{2}$ of the W doped niobium provokes a drastic modification in the morphology (Figure 4c). The materials present crystallite sizes between $10-30 \mu \mathrm{m}$ and $400 \mu \mathrm{m}$, approximately, for $\mathrm{NbW}$ and $\mathrm{NbW} / /$ $\mathrm{H}_{2} \mathrm{O}_{2}$, respectively. The SEM results suggest the occurrence of a nucleation process as related by Finney and Finke. ${ }^{17}$

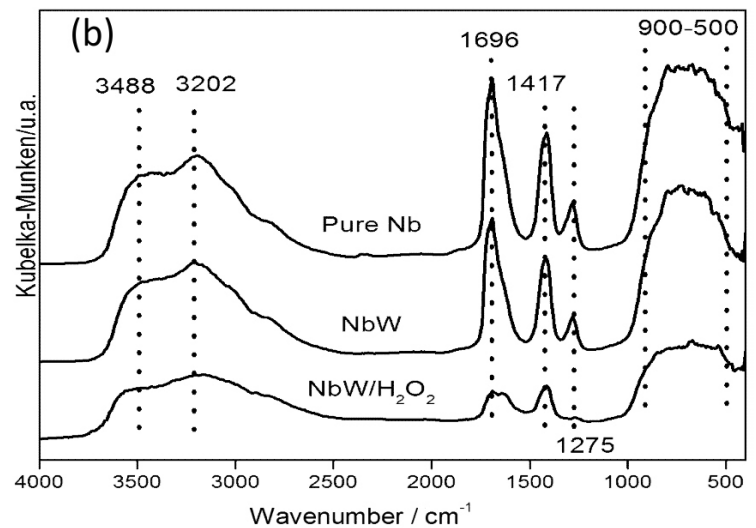

Figure 3. FTIR spectra of the synthetic niobia sample using (a) transmittance and (b) reflectance spectroscopy. 

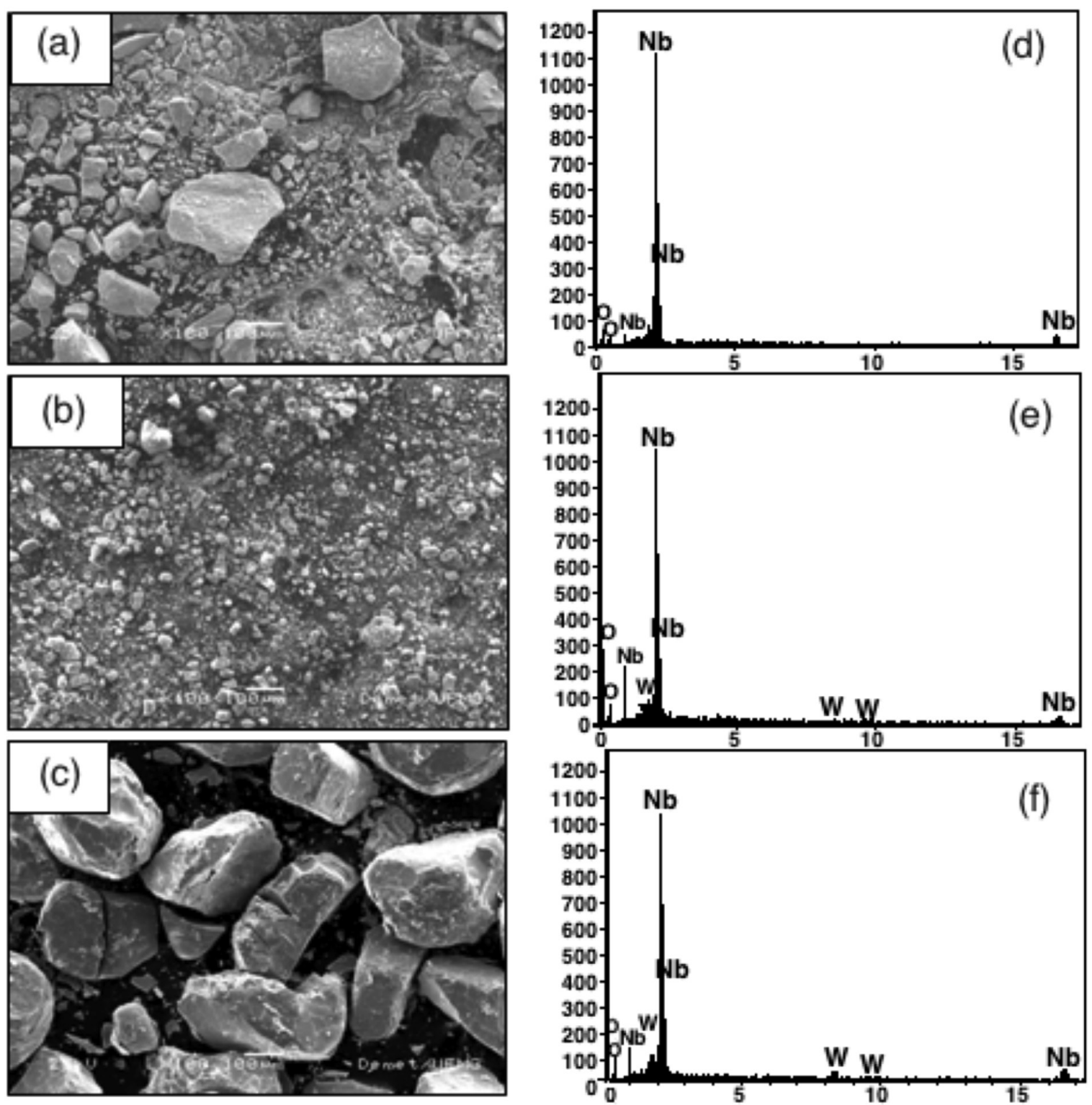

Figure 4. Scanning electron microscopy of the samples and EDS analysis for pure $\mathrm{Nb}(\mathrm{a})$ and (d), $\mathrm{NbW}$ (b) and (e), $\mathrm{NbW}_{/} / / \mathrm{H}_{2} \mathrm{O}_{2}$ (c) and (f).

The energy dispersive X-ray spectroscopy analysis (EDS) for pure $\mathrm{Nb}$ provided an approximate $\mathrm{Nb}$ level of $65 \%$ in mass. Regarding the sample containing tungsten $(\mathrm{NbW})$ (Figure 4e), signals of that element with level of $2.1 \%$ in mass are observed. There was a significant decrease in the level of $\mathrm{Nb}$ (55\% in mass) when compared to the pure $\mathrm{Nb}$ sample (Figure 4d). For the sample $\mathrm{NbW} / / \mathrm{H}_{2} \mathrm{O}_{2}$, the level of niobium obtained from the EDS analysis was $55 \%$ in mass (Figure 4f), however, the level of W went from $2.1 \%$ in NbW to $14.6 \%$ in mass for the sample $\mathrm{NbW} / / \mathrm{H}_{2} \mathrm{O}_{2}$. That result suggests that most internal $\mathrm{W}$ of the material is exposed to the surface with the treatment with $\mathrm{H}_{2} \mathrm{O}_{2}$, probably due to the dissolution of unstable niobium oxide crystallites.

The materials were also characterized by temperature programmed reduction (Figure 5a) and X-ray diffraction
(Figure 5b) in order to identify the phases present and the influence of the tungsten presence.

The pure niobium oxide (pure $\mathrm{Nb}$ ) presented two main reduction peaks centered at approximately 634 and $710^{\circ} \mathrm{C}$. Niobium oxide $\left(\mathrm{Nb}_{2} \mathrm{O}_{5}\right)$ can undergo reduction to oxides with oxidation states of $4+$ and $2+$, according to the equations below:

$$
\begin{aligned}
& \mathrm{Nb}_{2} \mathrm{O}_{5} \stackrel{\mathrm{H}_{2}}{\longrightarrow} 2 \mathrm{NbO}_{2}+\mathrm{H}_{2} \mathrm{O} \\
& 2 \mathrm{NbO}_{2} \stackrel{\mathrm{H}_{2}}{\longrightarrow} 2 \mathrm{NbO}+\mathrm{H}_{2} \mathrm{O}
\end{aligned}
$$

The literature relates that the formation of a dark blue solid $\left(\mathrm{NbO}_{2}\right)$ from $\mathrm{Nb}_{2} \mathrm{O}_{5}$ requires temperatures between 800-1300 ${ }^{\circ} \mathrm{C} .{ }^{4}$ For the $\mathrm{W}$ doped sample $(\mathrm{NbW})$, the main 



Figure 5. Temperature programmed reduction profiles and XRD analyses of the synthetics niobia.

reduction peaks occur at lower temperatures than those of the pure niobium oxide, centered at 458 and $499{ }^{\circ} \mathrm{C}$, showing that the presence of $\mathrm{W}$ in the niobium structure facilitates the reduction with $\mathrm{H}_{2}$. After the $\mathrm{H}_{2} \mathrm{O}_{2}$ treatment, the $\mathrm{NbW} / / \mathrm{H}_{2} \mathrm{O}_{2}$ sample presents a strong displacement to higher reduction temperatures of 575 and $683{ }^{\circ} \mathrm{C}$. That result is in agreement with the SEM data (Figure 4), in which the crystallites size increased after the $\mathrm{H}_{2} \mathrm{O}_{2}$ treatment, explaining the observed displacement.

In X-ray diffractograms (Figure 5b), the absence of reflections is observed regarding niobium oxides or tungsten for the pure $\mathrm{Nb}, \mathrm{NbW}$ samples and for $\mathrm{NbW} / / \mathrm{H}_{2} \mathrm{O}_{2}$, characterizing the presence of amorphous materials, which corroborates the data obtained by infrared spectroscopy.

\section{Methylene blue dye oxidation in the presence of $\mathrm{H}_{2} \mathrm{O}_{2}$}

The organic dye oxidation via heterogeneous catalysis was monitored by UV-Vis spectroscopy and the intermediates formation by electrospray ionization mass spectrometry (ESI/MS). ESI analysis was done to verify the effective oxidation of the dye, once the absence of color does not mean mineralization of the contaminant.

It can be observed in Figure 6a that using the pure $\mathrm{Nb}$ the removal occurs slowly up to $60 \mathrm{~min}$ of reaction, presenting about $20 \%$ of discoloration. However, after that time, an abrupt removal of the color occurs, reaching $80 \%$ after 90 min of reaction. This sample, after a previous treatment with hydrogen peroxide (pure $\mathrm{Nb} / / \mathrm{H}_{2} \mathrm{O}_{2}$ ), showed a strong discoloration at $90 \mathrm{~min}$, indicating that the treatment with $\mathrm{H}_{2} \mathrm{O}_{2}$ improves the catalytic activity in the oxidation of the dye. The catalytic activity showed by the synthetic niobia can be due to the surface groups, known as niobium peroxo complexes, formed by the presence of $\mathrm{H}_{2} \mathrm{O}_{2}$. These peroxo species are potentially oxygen donors to organic substrates in the liquid phase. ${ }^{11}$ In order to understand that behavior and to identify possible reaction intermediates,
ESI-MS studies were conducted after 60 and $90 \mathrm{~min}$ of reaction (Figure 6b). It can be clearly observed that after $60 \mathrm{~min}$ there is a decrease of the $\mathrm{m} / z=284$ signal related to cationic form of the dye. However, peaks are not observed regarding the formation of the reaction intermediates, suggesting removal by adsorption. After $90 \mathrm{~min}$ of reaction the $m / z=284$ signal disappearance completely, however with the appearance of the dye oxidation intermediates with $m / z=304$ and 369. At this reaction time, the $m / z$ signals appearing at $\mathrm{m} / \mathrm{z}=130,160,241$ and 268 are assumed to be related to dye oxidation intermediates, from fragmentations of the molecular structural ring that indicate the degradation of the organic compound may be brought to complete mineralization, as the total organic carbon analyses evidenced. It is evident, with these results, that the pure $\mathrm{Nb}$ needs some time $(90 \mathrm{~min})$ to become active and then promote a high removal of the MB dye. Similar studies were conducted for the $\mathrm{NbW}$ and $\mathrm{NbW} / / \mathrm{H}_{2} \mathrm{O}_{2}$ samples and presented in Figure 7.

Figure 7 a displays that the removal of the dye (monitored by UV-Vis spectroscopy) for the sample pretreated with $\mathrm{H}_{2} \mathrm{O}_{2}\left(\mathrm{NbW} / / \mathrm{H}_{2} \mathrm{O}_{2}\right)$ is significantly superior to the NbW sample, because the total dye removal occurs with only $30 \mathrm{~min}$ of reaction. In fact, ESI-MS studies, using the catalyst $\mathrm{NbW} / / \mathrm{H}_{2} \mathrm{O}_{2}$ (Figure 7b), show that after $30 \mathrm{~min}$ of reaction the signal regarding the MB dye disappears completely with the formation of several oxidation peaks and break of the dye structure. Those results clearly show the synergistic effect of the incorporation of $\mathrm{W}$ in the niobium oxide structure and the previous treatment with hydrogen peroxide on the removal capacity of organic compounds from the aqueous medium. After modifying the niobia through tungsten doping, treatment with $\mathrm{H}_{2} \mathrm{O}_{2}$ was carried out in order to increase the catalytic properties of the catalyzer by increasing the number of oxidizing groups throughout the entire surface of the material. A previous work showed that the catalytic activity by the 


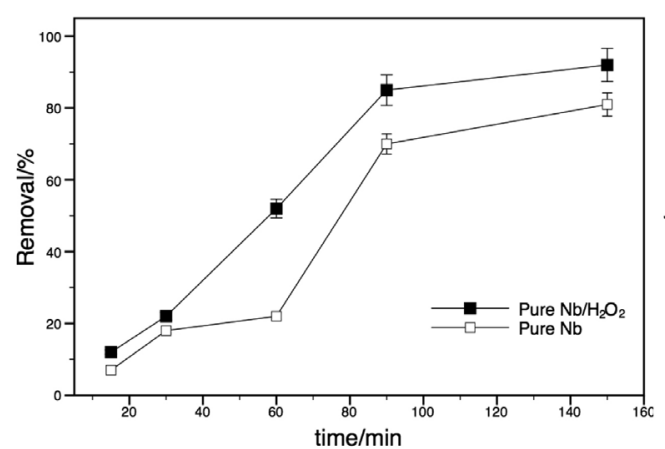

(a)

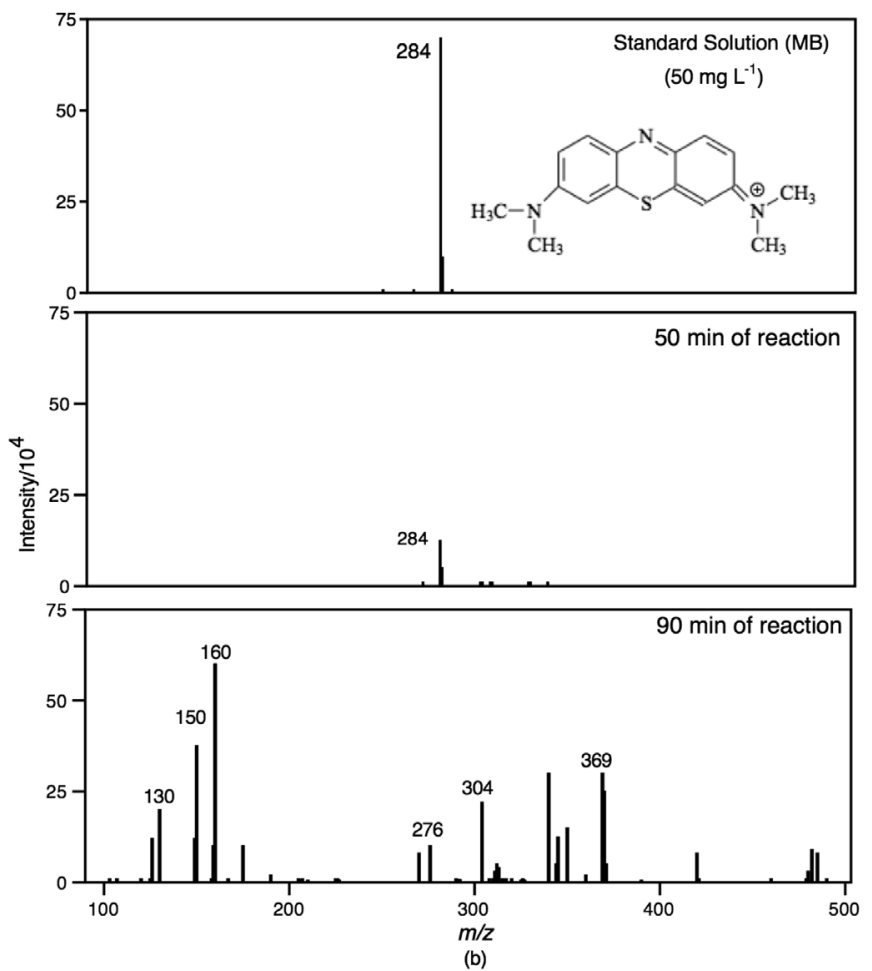

Figure 6. Discoloration measurements using methylene blue dye as model molecule in the presence of pure Nb (a) and ESI-MS analysis at different reactions times (b).

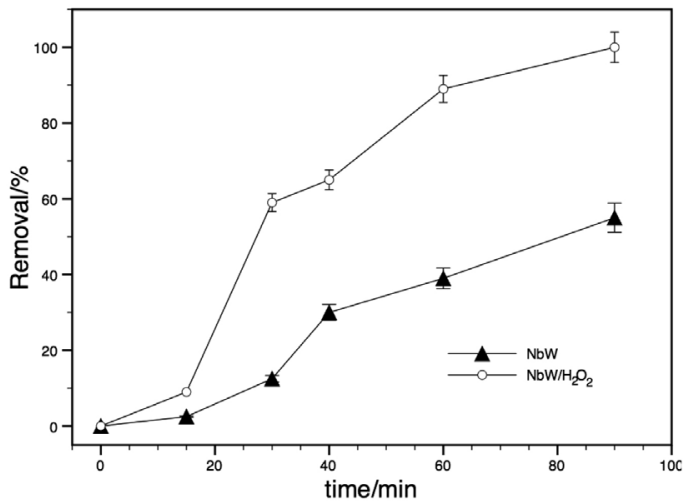

(a)
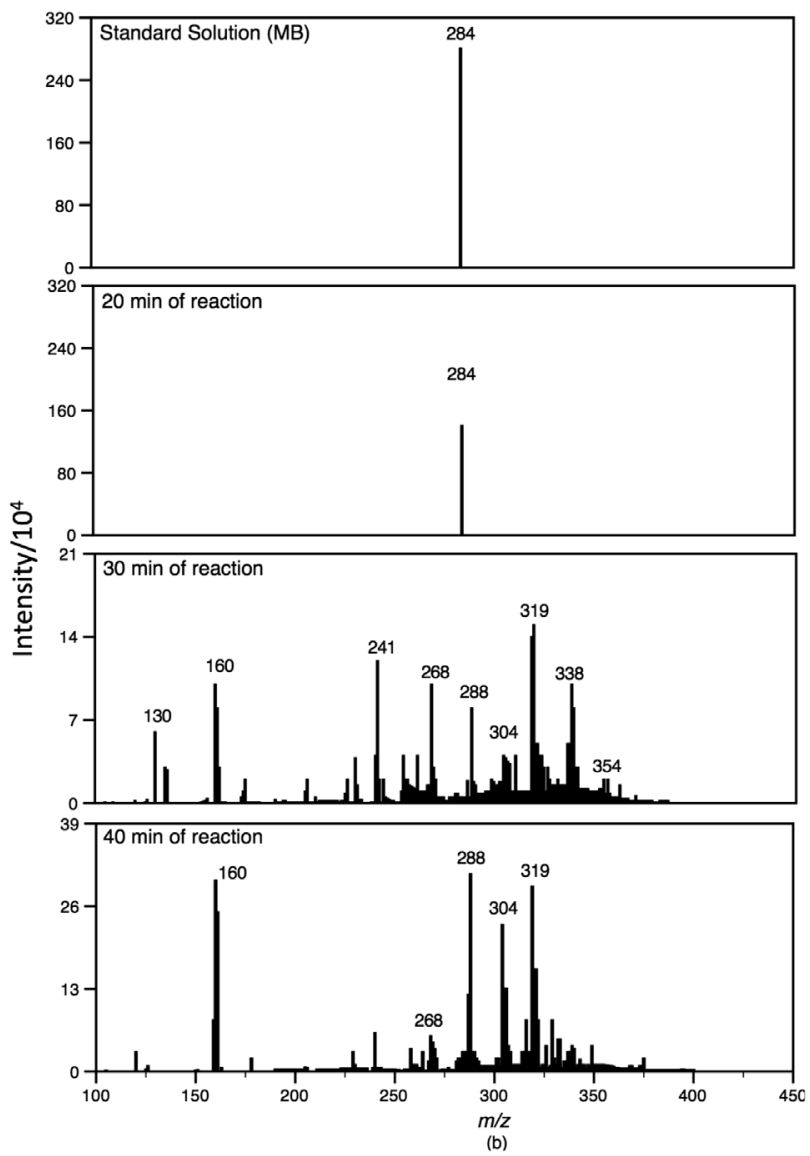

Figure 7. Discoloration measurements using methylene blue dye as model molecule in the presence of pure $\mathrm{Nb}$ and $\mathrm{NbW} / / \mathrm{H}_{2} \mathrm{O}_{2}$ (a) and ESI-MS at different reactions times using $\mathrm{NbW} / / \mathrm{H}_{2} \mathrm{O}_{2}$ (b). 
synthetic niobia could be due to the surface groups, known as niobium peroxo complexes, formed by the treatment with $\mathrm{H}_{2} \mathrm{O}_{2}{ }^{13}$ The presence of tungsten in the catalyst seems to facilitate the generation of surface peroxo groups.

The real removal of the organic compound was evaluated for the most active catalyst, $\mathrm{NbW} / / \mathrm{H}_{2} \mathrm{O}_{2}$, by analysis of total organic carbon in solution. The results are presented in Figure 8 (a). Figure 8 (b) presents some structural proposals for the intermediates observed in the ESI-MS analyses. The $\mathrm{NbW} / / \mathrm{H}_{2} \mathrm{O}_{2}$ catalyst removed approximately $55 \%$ of the organic carbon, evidencing a high mineralization capacity of the organic compound when compared with other oxides in similar systems. ${ }^{17}$
It is important to highlight that some $\mathrm{MB}$ dye reaction intermediates observed by ESI-MS suggest the transfer of oxygenated groups from the catalyst surface to the organic molecule. As related in the literature, the peroxo species, formed in the presence of transition metals, such as $\mathrm{Nb}$ and $\mathrm{W}$, and hydrogen peroxide, can donate such groups to the organic substrate in aqueous medium..$^{8-11}$ Therefore, after the dye oxidation, the presence of the oxidizer agent $\left(\mathrm{H}_{2} \mathrm{O}_{2}\right)$ would regenerate those groups on the surface, as schematized in stages (i) and (ii) in Figure 9. That mechanism, known as Mars van Krevelen, was observed for reactions involving niobium compounds and it was showed in this work that the tungsten presence into the structure of niobia can intensify this effect. ${ }^{18,19}$

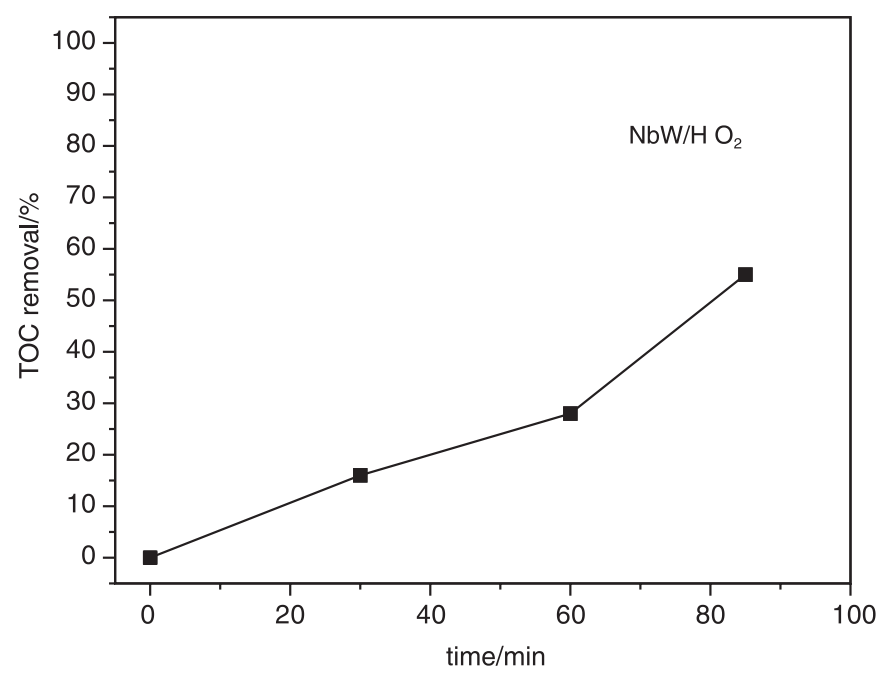

(a)<smiles>CN(C)c1ccc2nc3ccc(=[W](C)N(C)C)cc-3sc2c1</smiles><smiles></smiles>

$\underset{m / z=300}{\text { II }}$

III<smiles>C[13C](C)=c1cc(O)c2c(c1O)Sc1cc(N(C)C)cc(O)c1N=2</smiles>

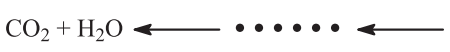<smiles>CCCC(CC(=O)O)N(C)C</smiles>

VI

$m / z=161$

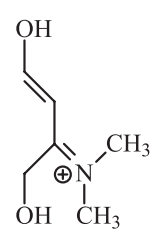
V $m / z=130$
IV

$m / z=332$

(b)

Figure 8. TOC analysis using $\mathrm{NbW} / / \mathrm{H}_{2} \mathrm{O}_{2}$ as catalyst (a) and a scheme with intermediates proposed for the oxidation of methylene blue dye $(\mathrm{m} / \mathrm{z}=284)$ by the catalysts. 
(i)

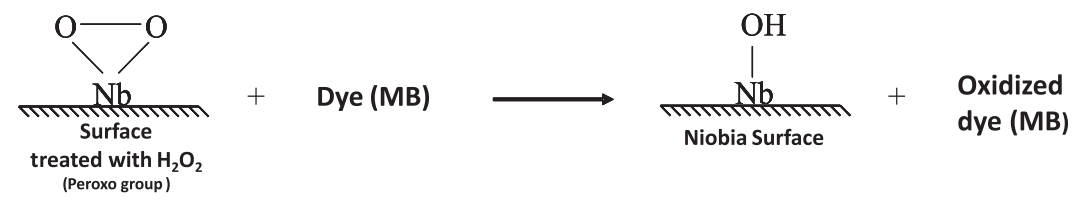

(ii)

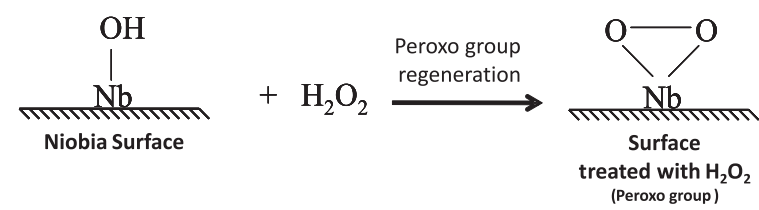

Figure 9. Scheme of the formation of peroxo niobium complex on niobia surface.

\section{Conclusions}

The innovative aspect of this work consists of the fact that the peroxo species, highly active, are formed on solid surfaces for application in heterogeneous catalysis. Furthermore, new niobium compound synthesis routes and modifications with $\mathrm{W}$ are proposed, promoting catalytic activity intensification of the catalysts.

The NbW sample, without previous treatment with $\mathrm{H}_{2} \mathrm{O}_{2}$, showed to be more efficient in the oxidation of the methylene blue dye, when compared to the pure niobia. $\mathrm{NbW} / / \mathrm{H}_{2} \mathrm{O}_{2}$ presented a slow removal up to $60 \mathrm{~min}$ of reaction that can be attributed to the necessity for the dye to accumulate on the niobia surface, when occurs the oxidation by the active sites (peroxo groups) on the catalyst surface.

\section{Acknowledgments}

The authors wish to thank the CNPq and FAPEMIG for the financial support and the CBMM-Brazil for the supply of the niobium salt.

\section{References}

1. Esparza, P.; Borges, M. E.; Díaz, L.; Alvarez-Galván, M. C.; Fierro, J. L. G.; Appl. Catal., A 2010, 388, 7.

2. Rodrigues, C. S. D.; Madeira, L. M.; Boaventura, R. A. R.; J. Hazard. Mater. 2009, 1721551.

3. Pergher, S. B. C.; Oliveira, L. C. A.; Smaniotto, A.; Petkowicz, D. I.; Quim. Nova 2005, 28, 751 .

4. Nowak, I.; Ziolek, M.; Chem. Rev. 1999, 99, 3603.

5. Tanabe, K.; Catal. Today 2003, 78, 65.
6. Abdel-Rehim, M. A.; Santos, A. C. B; Camorim, V. L. L.; Faro Junior, A. C.; Appl. Catal., A 2006, 305, 211.

7. Prado, A. G. S.; Bolzon, L. B.; Pedroso, C. P.; Moura, A. O.; Costa, L. L.; Appl. Catal., B 2008, 82, 219.

8. Guimaraes, I. R.; Oliveira, L. C. A.; Queiroz, P. F.; Ramalho, T. C.; Pereira, M. C.; Fabris, J. D.; Ardisson, J. D.; Appl. Catal., A 2008, 347, 89 .

9. Bayot, D.; Devillers, M.; Coord. Chem. Rev. 2006, 250, 2610.

10. Maniatakou, A.; Makedonas, C.; Mitsopoulou, C. A.; Raptopoulou, C.; Rizopoulou, I.; Terzis, A.; Karaliota, A.; Polyhedron 2008, 27, 3398.

11. Esteves, A.; Oliveira, L. C. A.; Ramalho, T. C.; Gonçalves, M.; Anastácio, A. S.; Carvalho, H. W. P.; Catal. Commun. 2008, 10, 330 .

12. Oliveira, L. C. A.; Ramalho, T. C.; Ramalho, E. F.; Gonçalves, M.; Oliveira, D. Q. L.; Pereira, M. C.; Fabris, J. D.; Appl. Catal., B 2008, 83, 169.

13. Silva, A. C.; Oliveira, D. Q. L.; Oliveira, L. C. A.; Anastácio, A. S.; Ramalho, T. C.; Lopes, J. H.; Carvalho, H. W. P.; Torres, C. E. R.; Appl. Catal., A 2009, 357, 79.

14. Ziolek, M.; Sobczak, I.; Lewandowska, A.; Nowak, I.; Decyk, P.; Renn, M.; Jankowska, B.; Catal. Today 2001, 70, 169.

15. Ristic, M.; Popovic, S.; Music, S.; Mater. Lett. 2004, 58, 2658.

16. Narendar, Y.; Messing, G. L.; Chem. Mater. 1997, 9, 580.

17. Finney, E. E.; Finke, R. G.; J. Colloid Interface Sci. 2008, 317, 35.

18. Mars, P.; van Krevelen, D. W.; Chem. Eng. Sci. 1954, 3, 41.

19. Ferraz, W.; Oliveira, L. C. A.; Dallago, R.; Conceição, L.; Catal. Commun. 2007, 8, 131.
Submitted: September 19, 2011

Published online: March 1, 2012 